\title{
Effects of 8 weeks of continuous positive airway pressure on abdominal adiposity in obstructive sleep apnoea
}

\author{
Sheila Sivam*,\#, Craig L. Phillips*, ,+, Michael I. Trenell ${ }^{\S}$, Brendon J. Yee*,\#, , \\ Peter Y. Liü, ${ }^{\sharp, f, * *}$, Keith K. Wong ${ }^{\star, \#, \oplus}$ and Ronald R. Grunstein ${ }^{\star, \#, \uparrow}$
}

ABSTRACT: The aim of the present study was to investigate the effect of continuous positive airway pressure (CPAP) treatment on regional adipose tissue distribution in patients with moderate or severe obstructive sleep apnoea.

Patients received both therapeutic and sham CPAP in a random order for 2 months each with an intervening 1-month washout. Abdominal subcutaneous, visceral and liver fat were quantified using magnetic resonance imaging (MRI) and magnetic resonance spectroscopy (MRS). Liver enzymes and plasma glucose were also determined. Measurements were obtained at baseline and at the end of both treatment arms.

38 eligible patients were randomly assigned to a treatment order, with 27 patients having complete MRI/MRS data. No significant difference was observed in subcutaneous $\left(-28.6 \mathrm{~cm}^{3} ; \mathrm{p}=0.49\right)$ or visceral $\left(-16.8 \mathrm{~cm}^{3} ; p=0.59\right)$ adipose tissue, intrahepatic lipid $(-0.2 \% ; p=0.21)$, or fasting glucose measurements $\left(-0.1 \mathrm{mmol} \cdot \mathrm{L}^{-1} ; \mathrm{p}=0.46\right)$ between treatment modalities. Alkaline phosphatase decreased $\left(-3.1 \mathrm{U} \cdot \mathrm{L}^{-1} ; \mathrm{p}=0.02\right)$ while on therapeutic CPAP compared with sham CPAP but other liver enzymes, including aspartate aminotransferase $\left(0.3 \mathrm{U} \cdot \mathrm{L}^{-1} ; \mathbf{p}=\mathbf{0 . 8 2}\right)$, alanine aminotransferase (1.34 $\left.\mathrm{U} \cdot \mathrm{L}^{-1} ; \mathrm{p}=0.59\right)$ and $\gamma$-glutamyltransferase $\left(-2.3 \mathrm{U} \cdot \mathrm{L}^{-1} ; \mathrm{p}=0.33\right)$, remained unchanged.

In this first randomised, sham-controlled trial, there was no change in adipose tissue distribution after 8 weeks of therapeutic CPAP compared with 8 weeks of sham CPAP. Longer duration of CPAP use may be necessary to demonstrate a difference.

KEYWORDS: Fasting glucose, hepatic fat, liver function test, subcutaneous fat, visceral fat

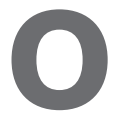
bstructive sleep apnoea (OSA) affects at least 4 and $2 \%$ of middle-aged males and females, respectively [1]. Central (or abdominal) obesity is a known risk factor for OSA and is strongly linked to insulin resistance. There is increasing evidence for a correlation between OSA and worsened glucose intolerance, although it remains controversial whether this relationship is entirely independent of obesity [2]. Nevertheless, several clinical trials have suggested an improvement in insulin resistance with continuous positive airway pressure (CPAP) treatment for OSA [3, 4].

Adipose tissue in the abdomen is distributed amongst the subcutaneous layer of the skin, the viscera and the liver. It is hypothesised that deposition of fat in the viscera and liver reflects the inability of the subcutaneous tissue to absorb and store excess dietary triglycerides [5]. Both visceral and subcutaneous fat are associated with increased insulin resistance; however, overweight subjects with excess visceral fat have the most insulin resistance [5]. Furthermore, the severity of upper airway obstruction and hypoxaemia secondary to OSA appears to better correlate with the amount of visceral fat than clinical measures of obesity, including body mass index (BMI) [6].

Currently, it is unclear whether CPAP use results in a reduction of insulin resistance-associated visceral fat. Some observational studies have shown a reduction $[7,8]$ while others showed no change $[3,9,10]$. Factors that could contribute to the differences observed include mean CPAP compliance, duration of treatment and OSA severity. Importantly, there are presently no sham-controlled randomised trials examining central obesity in OSA and its response to CPAP. Several studies investigating the combination of improved dietary and exercise measures and weight loss-promoting medications have shown a greater reduction in visceral fat compared with subcutaneous fat [11].

OSA has also been shown to aggravate components of the metabolic syndrome, including
AFFILIATIONS

*Sleep and Circadian Research Group, Woolcock Institute of Medical Research,

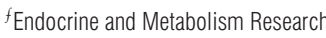
Group, Woolcock Institute of Medical Research, Glebe, NSW,

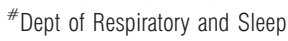
Medicine, Royal Prince Alfred Hospital, Camperdown, NSW, 'Discipline of Sleep Medicine, Sydney Medical School, University of Sydney, Sydney, NSW, and +Dept of Respiratory and Sleep Medicine, Royal North Shore Hospital, St Leonards, NSW, Australia.

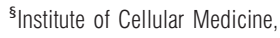
Newcastle University, Newcastle upon Tyne, UK.

${ }^{* *}$ Los Angeles Biomedical Research Institute at Harbor-University of California Los Angeles Medical Center, Torrance, CA, USA.

CORRESPONDENCE

S. Sivam

Sleep and Circadian Research Group Woolcock Institute of Medical Research

P0 Box M77

Missenden Road

NSW 2050

Australia

E-mail: sheila.sivam@sydney.edu.au

Received:

Oct 122011

Accepted after revision:

Jan 052012

First published online: Jan 202012 
hyperinsulinaemia and may, thus, indirectly contribute to the development of a fatty liver [12]. Patients with nonalcoholic fatty liver disease (NAFLD) are often asymptomatic and many have normal liver function tests. Nevertheless, patients can be diagnosed with NAFLD after mild elevations of liver enzymes are discovered [13]. Markers of hypoxia have been demonstrated to be associated with elevated serum aminotransferase levels [14]. Similarly to visceral fat, however, there are contrasting results on the effect of nasal CPAP on the biochemical markers of NALFD in patients with OSA $[12,15,16]$.

This randomised, sham-controlled crossover study investigated the effect of CPAP treatment for 8 weeks versus sham CPAP for 8 weeks in patients with moderate-to-severe hypoxaemic OSA on the volume and distribution of abdominal adipose tissue, liver fat, liver enzymes and glucose.

\section{METHODS}

\section{Participants}

The protocol has previously been reported in a study that assessed the effect of CPAP treatment on post-prandial lipidaemia [17]. Details of randomisation, allocation concealment and blinding, and the flow of patients through the trial are included in the original report. Briefly, we recruited patients from sleep apnoea clinics who were aged $>21$ yrs, with OSA severity in the upper moderate or severe range (apnoeahypopnoea index $(\mathrm{AHI}) \geqslant 25$ events $\cdot \mathrm{h}^{-1}$ ) with a hypoxic component (oxygen desaturation index $\geqslant 20$ events $\cdot h^{-1}$ ). We excluded patients with $\mathrm{BMI}>35 \mathrm{~kg} \cdot \mathrm{m}^{-2}$, uncontrolled type 2 diabetes and patients who had previously used CPAP. The exclusion of patients with $\mathrm{BMI}>35 \mathrm{~kg} \cdot \mathrm{m}^{-2}$ was solely because such individuals cannot usually fit into a magnetic resonance imaging (MRI) scanner. Patients who consumed $>140 \mathrm{mg}$ of alcohol per week and those with known liver disease were also excluded. Other selection criteria are available from the Australian and New Zealand Clinical Trials Registry (www.anzctr.org.au) (identifier number ACTRN 12605000066684). The diagnosis of sleep apnoea was based on full overnight polysomnography in a clinical laboratory prior to recruitment. End-of-treatment polysomnography was performed on either therapeutic or sham CPAP. Apnoeas and hypopnoeas were scored using standard scoring techniques [18]. The study protocol was approved by the Human Research Ethics Committee of the Sydney South West Area Health Service (\#X05-0128) at Royal Prince Alfred Hospital (Sydney, NSW, Australia). All subjects gave written informed consent prior to study participation.

\section{Study design}

Patients who met the inclusion/exclusion criteria were randomised to receive CPAP (Remstar Auto; Philips Respironics, Murrysville, PA, USA) or sham CPAP for 8 weeks each in a crossover design with an intervening 1-month washout period between treatments (fig. 1). Sham CPAP devices are identical in appearance to the therapeutic devices except that the pressure delivered at the mask remains at $0.5 \mathrm{cmH}_{2} \mathrm{O}$, thus having no effect on sleep disordered breathing. In contrast, therapeutic CPAP was set to a pressure that prevented most sleep disordered breathing. This was determined during an at-home pressure determination study as previously described [17]. Compliance data from both devices was obtained from machine

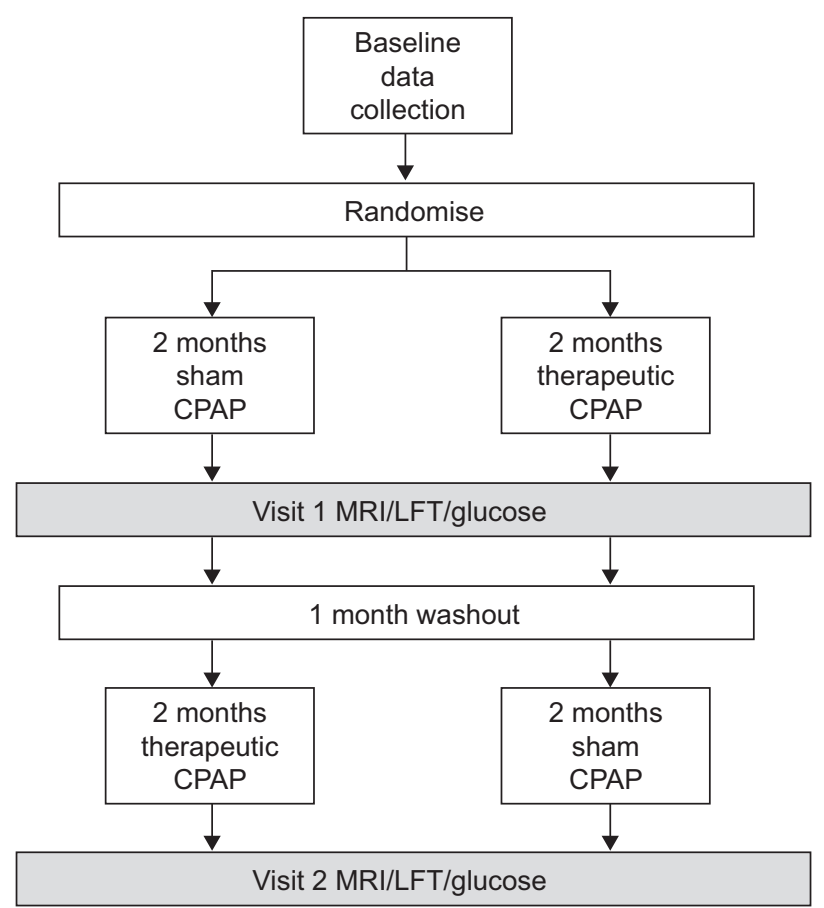

FIGURE 1. Study protocol. CPAP: continuous positive airway pressure; MRI: magnetic resonance imaging; LFT: liver function test.

downloads at the end of each treatment arm. Subjects did not change their exercise regime, diet or medications throughout the duration of the study.

\section{Imaging and biochemical testing}

MRI and magnetic resonance spectroscopy (MRS) were used to quantify abdominal and liver fat. MRI measurements were obtained at baseline and at the end of both treatment arms (fig. 1). An average of 10 (range 5-10) T1-weighted axial images (7 mm thick, 1-mm gap) were acquired during a breath-hold starting at the level of the fourth lumbar vertebra (L4). Contiguous DICOM ${ }_{\circledR}$ (Digital Imaging and Communications in Medicine) protocol (National Electrical Manufacturer's Association, Rosslyn, VA, USA) images were analysed for quantification of subcutaneous and visceral adipose tissue using specialised validated software (Hippo Fat ${ }^{\mathrm{TM}}$; CNR Institute of Clinical Physiology, Pisa, Italy) [19]. Contours lining the inner and outer margin of subcutaneous adipose tissue and the inner margin of the abdominal muscle layer were automatically generated for each image. These were then manually adjusted by eye, as necessary [20], to encapsulate the entire subcutaneous and visceral compartments of each analysed slice. The software then performs an automated analysis of pixel intensity to discriminate tissue class (air, adipose tissue and nonadipose tissue). Investigators, including those undertaking adipose tissue quantification analysis, were blinded throughout the study to patient treatment groups.

MRS liver fat measurements were performed using a 1.5-T Philips Achieva scanner (Philips Medical Systems, Best, the Netherlands). Following an 8-h fast, intrahepatic lipid (IHL) was measured by localised ${ }^{1} \mathrm{H}-\mathrm{MRS}$ (point-resolved spectroscopy; repetition time $3,000 \mathrm{~ms} / 35 \mathrm{~ms} ; 3 \times 3 \times 3-\mathrm{cm}$ voxel) (SENSE Torso Array; Philips Medical Systems). Blinded 
quantification of the spectra (water and $\mathrm{CH}_{2}$ resonances) was performed using jMRUI version 3.0 (The MRUI Project, Barcelona, Spain) [21]. Following manual first- and secondorder phase correction, spectra were analysed using a nonlinear least-squares algorithm (Advanced Method for Accurate, Robust and Efficient Spectral Fitting). IHL was expressed as a percentage of liver volume, corrected for the proton densities of water and lipid [22]. Measurements of hepatic fat by spectroscopy have been validated against lipid content determined by histology [22].

Liver enzymes and glucose levels were measured in the fasting state at the end of each 8-week intervention arm.

\section{Statistical methods}

The final analyses included 27 patients who had completed the crossover trial, regardless of compliance with either therapeutic or sham CPAP. Order effect was analysed using unpaired t-tests. Main outcomes were analysed using paired t-tests. The effect of compliance with therapeutic CPAP on visceral and subcutaneous fat and IHL at the end of the CPAP period was analysed using a compliance cut-off point of $4 \mathrm{~h}$ with unpaired t-tests. Correlation analysis was also performed between compliance (hours) and visceral and subcutaneous fat and IHL. Order effect was examined by comparing the difference in abdominal fat between CPAP and sham CPAP for subjects who received CPAP in the first arm as opposed to the second arm.

Data was analysed with the statistical software package STATA ${ }^{\mathrm{TM}}$ version 10 (StataCorp, College Station, TX, USA).

\section{RESULTS}

A total of 29 patients completed the trial [17]. Complete MRI and laboratory data were available for 27 participants. One patient was excluded because they had poor-quality MRI images that could not be analysed using the Hippo Fat ${ }^{\mathrm{TM}}$ software, and another participant developed claustrophobia and subsequently missed the final MRI appointment, thus having incomplete data. Nine participants withdrew or were withdrawn post-randomisation, as previously reported [17].

Patient demographics, anthropometrics, diagnostic polysomnography data and baseline biochemistry data are shown in table 1, and polysomnographic, CPAP compliance and residual AHI data obtained at the end of the CPAP and sham treatment arms are outlined in table 2. No significant differences were observed in either subcutaneous or visceral fat, IHL, BMI, or fasting glucose measurements between treatment arms (table 3). The visceral/subcutaneous fat ratio was the same in the CPAP (0.44) and sham (0.44) arms. In addition, there was no significant difference in IHL when the data were reanalysed excluding the two diabetic patients (mean CPAP - sham CPAP IHL difference $-0.2 ; \mathrm{p}=0.34$ ). There was no effect of compliant $(>4 \mathrm{~h})$ versus noncompliant CPAP use on the baseline-to-CPAP change in fat $(p=0.27,0.48$ and 0.46 for subcutaneous and visceral fat and IHL, respectively), nor was there any correlation between change in subcutaneous or visceral fat, or IHL with compliance with therapeutic CPAP as a continuous variable $(r=-0.07(p=0.71), r=0.17(p=0.39)$ and $r=0.24(p=0.25)$, respectively). In addition, there was no effect of order of CPAP treatment exposure on baseline to CPAP change in adipose tissue.

\begin{tabular}{|c|c|c|}
\hline TABLE 1 & \multicolumn{2}{|c|}{$\begin{array}{l}\text { Patient demographic, anthropometric and } \\
\text { baseline data }\end{array}$} \\
\hline \multicolumn{3}{|c|}{ Demographics } \\
\hline Age yrs & & $47 \pm 13$ \\
\hline Males/fema & s $n$ & $26 / 1$ \\
\hline $\mathrm{BMl} \mathrm{kg} \cdot \mathrm{m}^{-2}$ & & $31.3 \pm 3.8$ \\
\hline \multicolumn{3}{|c|}{ Medical history and medication $\mathrm{n}$} \\
\hline Hypertensi & & 9 \\
\hline Type 2 dial & tes & 2 \\
\hline Hyperchole & terolaemia & 10 \\
\hline Antihyperte & sive agents & 9 \\
\hline Oral hypog & caemic agents & 1 \\
\hline Insulin & & 0 \\
\hline Statins & & 7 \\
\hline \multicolumn{3}{|c|}{ Sleep apnoea } \\
\hline AHI events & & $37.2 \pm 24.7$ \\
\hline ODI events & & $30.3 \pm 22.6$ \\
\hline TST with $S$ & $p_{2}<90 \% \%$ & $7.1 \pm 11.7$ \\
\hline Minimum S & $\mathrm{O}_{2} \%$ & $78.0 \pm 11.4$ \\
\hline ESS score & & $10.0 \pm 4.8$ \\
\hline \multicolumn{3}{|l|}{ LFT } \\
\hline$A L P^{\#} U \cdot L^{-1}$ & & $72.5 \pm 13.9$ \\
\hline AST" $U \cdot L^{-1}$ & & $26.6 \pm 8.1$ \\
\hline$A L T^{*} U \cdot L^{-1}$ & & $41.1 \pm 19.9$ \\
\hline $\mathrm{GGT}^{+} \mathrm{U} \cdot \mathrm{L}^{-}$ & & $33.9 \pm 17.5$ \\
\hline Total prote & $g \cdot L^{-1}$ & $74.0 \pm 4.2$ \\
\hline Albumin ${ }^{f} \mathrm{~g}$ & & $45.3 \pm 2.3$ \\
\hline Bilirubin $\# \#$ & $\mathrm{~mol} \cdot \mathrm{L}^{-1}$ & $12.9 \pm 6.5$ \\
\hline Fasting gluc & 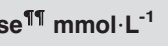 & $5.7 \pm 1.6$ \\
\hline \multicolumn{3}{|c|}{ Adipose tissue } \\
\hline Subcutane & Is fat $\mathrm{cm}^{3}$ & $2784.9 \pm 946.9$ \\
\hline Visceral fat & & $1179.7 \pm 530.9$ \\
\hline IHL \% & & $5.2 \pm 2.1$ \\
\hline \multicolumn{3}{|c|}{ 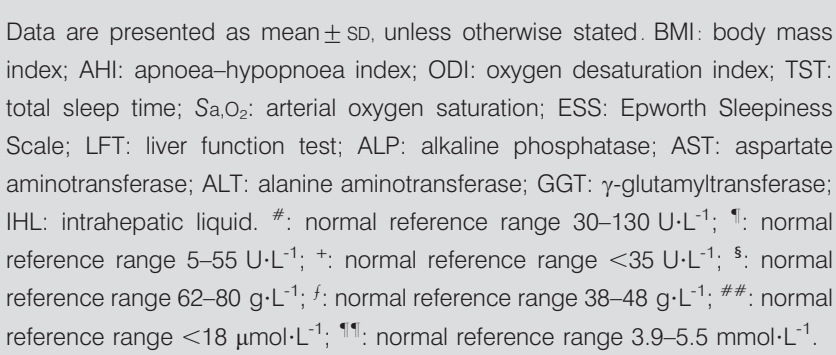 } \\
\hline
\end{tabular}

As with the adipose tissue data, there was also no change in most liver enzymes. Aspartate aminotransferase (AST), alanine aminotransferase (ALT), $\gamma$-glutamyltransferase (GGT), bilirubin, total protein and albumin remained unchanged; however, alkaline phosphatase (ALP) was lower while on CPAP compared with sham. Mean values for all baseline liver function tests were within the normal range; however, half our patients had mildly elevated liver enzyme levels. No randomised patient commenced any new medication or changed existing medication doses during the trial.

\section{DISCUSSION}

This is the first sham-controlled randomised study to test the effect of CPAP treatment for OSA on abdominal adipose tissue 
TABLE 2 End-of-treatment polysomnography data

\begin{tabular}{lccc} 
Characteristics & CPAP & Sham & p-value \\
\hline AHI events $\cdot \mathbf{h}^{-1}$ & $6.9 \pm 11.1$ & $38.7 \pm 28.7$ & $<0.00001$ \\
ODI events $\mathbf{h}^{-1}$ & $5 \pm 8.4$ & $38.1 \pm 23.4$ & $<0.00001$ \\
TST wih $\mathrm{Sa}, \mathbf{O}_{\mathbf{2}}<\mathbf{9 0} \% \%$ & $0.8 \pm 2.1$ & $10.1 \pm 12.0$ & 0.0005 \\
Minimum $\mathrm{Sa}, \mathbf{O}_{2} \%$ & $89.5 \pm 7.1$ & $79.5 \pm 8.9$ & 0.0001 \\
Treatment compliance $\boldsymbol{h} \cdot$ night $^{-1}$ & $4.6 \pm 2.0$ & $3.4 \pm 2.2$ & 0.003 \\
ESS score & $7.7 \pm 4.4$ & $9.4 \pm 4.2$ & 0.02 \\
\hline
\end{tabular}

Data are presented as mean $\pm \mathrm{SD}$, unless otherwise stated. CPAP: continuous positive airway pressure; AHI: apnoea-hypopnoea index; ODI: oxygen desaturation index; TST: total sleep time; $\mathrm{Sa}_{2} \mathrm{O}_{2}$ : arterial oxygen saturation; ESS: Epworth Sleepiness Scale.

distribution. The study failed to demonstrate any beneficial influence of 8 weeks of therapeutic CPAP compared with sham $\mathrm{CPAP}$ on the reduction of subcutaneous, visceral or hepatic fat in patients with moderate-to-severe obstructive sleep apnoea. In an analysis of secondary outcomes, while there was a significant reduction in ALP, no other significant differences were observed in liver enzymes or fasting glucose measurements.

CPAP has been shown to have varying effects on abdominal subcutaneous and visceral adipose tissue distribution. Studies by our group [7] and CHIN et al. [8] observed a reduction in visceral fat in patients with severe OSA after 3 and 6 months of CPAP use, respectively. In the former study, this difference was only demonstrated among regular CPAP users, who had an average compliance of $6 \mathrm{~h}$ per night, versus irregular CPAP users, with a mean of $2 \mathrm{~h}$ use per night. The latter study showed a reduction in visceral fat in patients who either maintained a stable body weight or who lost weight while on CPAP. A decrease in subcutaneous fat, however, was only observed in patients who had a reduction in body weight. In the present study, although our patients maintained a stable body weight throughout the trial, there was no accompanying change in visceral fat with CPAP use relative to sham CPAP. In contrast to the studies with positive findings, a more recent nonrandomised observational study by MUNZER et al. [9] failed to demonstrate a reduction in subcutaneous or visceral fat after 8 months of CPAP use, where compliance with CPAP averaged $6 \mathrm{~h}$ per night. Similar results were also shown in an observational study by VGONTZAS et al. [10] in which OSA patients were treated with nasal CPAP for 3 months. Although the authors stated that there was a reduction in visceral fat in a subgroup analysis of patients with high CPAP adherence ( $>4 \mathrm{~h}$ use per night; $\mathrm{n}=10)$, the published p-value was 0.2 [10]. This discrepancy between studies could be related to a difference in measurement techniques (computed tomography (CT) versus MRI); however, both MRI- and CTdetermined fat analysis are proven to be accurate and reproducible [23]. An alternative explanation may be related to differences in CPAP compliance; however, previously published negative studies show no difference even in compliant patients with $>5 \mathrm{~h}$ [3] and $6 \mathrm{~h}$ [9] of use. Furthermore, we could not demonstrate any correlation between compliance with CPAP and changes in fat content.

All previously published studies investigating the effects of CPAP on visceral fat $[3,7-10]$ involved participants with a mean $\mathrm{AHI}$ in the severe range, with three reporting a minimum oxygen saturation between 62 and $72 \%[7,8,10]$. Subjects in four out of five studies $[3,7,9,10]$ had a mean BMI $>30 \mathrm{~kg} \cdot \mathrm{m}^{-2}$ while the last study had an average BMI of $28 \mathrm{~kg} \cdot \mathrm{m}^{-2}$. Length of treatment did not seem to affect the outcome as there are both uncontrolled positive studies of 3 months [7] and 6 months [8] duration and negative studies with 3 months [3] and 6 months [9] treatment duration.

TABLE 3 Effects of continuous positive airway pressure (CPAP) versus sham CPAP

\begin{tabular}{|c|c|c|c|c|}
\hline & CPAP & Sham & Mean CPAP - sham difference $(95 \% \mathrm{Cl})$ & $p$-value \\
\hline \multicolumn{5}{|l|}{ Adipose tissue } \\
\hline Subcutaneous fat $\mathrm{cm}^{3}$ & $2767.8 \pm 882.6$ & $2796.4 \pm 960.2$ & $-28.6(-113.4-56.1)$ & 0.49 \\
\hline Visceral fat $\mathrm{cm}^{3}$ & $1222.5 \pm 526.1$ & $1239.2 \pm 563.0$ & $-16.8(-79.9-46.4)$ & 0.59 \\
\hline IHL \% & $5.4 \pm 1.8$ & $5.6 \pm 1.7$ & $-0.2(-0.6-0.1)$ & 0.21 \\
\hline \multicolumn{5}{|l|}{ LFT } \\
\hline$A L T^{\bullet} U \cdot L^{-1}$ & $39.8 \pm 16.2$ & $38.4 \pm 16.5$ & $1.3(-3.7-6.4)$ & 0.59 \\
\hline $\mathrm{GGT}^{+} U \cdot \mathrm{L}^{-1}$ & $40.2 \pm 21.5$ & $42.5 \pm 26.8$ & $-2.3(-6.9-2.4)$ & 0.33 \\
\hline Total protein $\mathrm{g}^{\S} \mathrm{L}^{-1}$ & $73.3 \pm 4.1$ & $73.3 \pm 4.7$ & $0(-1-0.9)$ & 0.94 \\
\hline Albumin $\mathrm{g} \cdot \mathrm{L}^{-1}$ & $45.3 \pm 2.1$ & $45.3 \pm 2.2$ & $0(-0.6-0.5)$ & 0.89 \\
\hline Bilirubin ${ }^{\# \#} \mu \mathrm{mol} \cdot \mathrm{L}^{-1}$ & $10.8 \pm 5.9$ & $11.1 \pm 7.1$ & $-0.2(-1.7-1.2)$ & 0.75 \\
\hline Fasting glucose ${ }^{\text {} \tau} \mathrm{mmol} \cdot \mathrm{L}^{-1}$ & $5.5 \pm 1.1$ & $5.6 \pm 1.0$ & $-0.1(-0.4-0.2)$ & 0.46 \\
\hline
\end{tabular}

Data are presented as mean \pm SD, unless otherwise stated. IHL: intrahepatic liquid; LFT: liver function test; ALP: alkaline phosphatase; AST: aspartate aminotransferase; ALT: alanine aminotransferase; GGT: $\gamma$-glutamyltransferase; BMI: body mass index. ${ }^{*}$ : normal reference range $30-130 \mathrm{U} \cdot \mathrm{L}^{-1}$; ${ }^{\bullet}$ : normal reference range $5-55 \mathrm{U} \cdot \mathrm{L}^{-1}$;

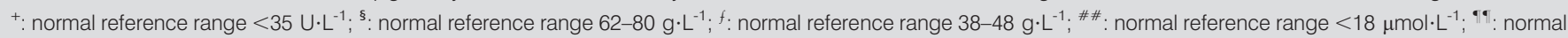
reference range $3.9-5.5 \mathrm{mmol} \cdot \mathrm{L}^{-1}$ 
The influence of CPAP on liver function and liver fat are equally conflicting. A study by KOHLER et al. [12] did not show a beneficial effect of therapeutic CPAP on liver enzymes (AST and ALT) over a 1-month period; however, CHIN et al. [15] demonstrated reduced overnight mean increases in aminotransferase levels after the first night of nasal CPAP treatment. Our study confirmed the lack of reduction in AST, ALT and GGT over a 2-month period; however, we did not measure short-term (overnight) changes in enzymes. The significance of an isolated reduction in ALP is also unclear, particularly as all liver enzymes were either normal or only mildly elevated. CPAP did not significantly change either albumin, total protein or bilirubin, reflecting no biochemical effect on the synthetic and detoxification function of the liver. To our knowledge, no prior studies have reported on this.

Visceral fat accumulation is an independent predictor of allcause mortality in males [24]. Post-prandial lipidaemia has also been shown to predict incident cardiovascular-related morbidity and mortality [25]. There is also data suggesting that both visceral [26, 27] and hepatic [28] fat accumulation are important factors involved in increasing post-prandial lipidaemia, particularly in glucose-intolerant or diabetic patients. In the context of OSA, although central obesity and fasting dyslipidaemia commonly occur [2], there are no robust data to suggest that either improves with CPAP treatment. However, we have recently shown that treatment of OSA with CPAP reduces postprandial lipids after only 8 weeks [17]. In the present study, although we could not also demonstrate significant reductions in abdominal or liver fat over a similar treatment period, an uncontrolled study using CPAP that assessed liver fat over 23 yrs did demonstrate a reduction in liver fat [16]. Hence, it is possible that a longer treatment period may eventually also show a benefit $[17,28]$.

Fasting glucose measurements obtained at baseline and after 8 weeks of CPAP use also did not improve in our study. While these do not directly indicate alterations in insulin sensitivity, they do provide a guide for altered glucose homeostasis. Nevertheless, these results are consistent with prior large randomised, sham-controlled trials that showed no significant difference in haemoglobin A1c levels and measures of insulin sensitivity with CPAP use in both diabetics [29] and nondiabetics [30]. LAM et al. [3] showed a reduction in insulin sensitivity as measured by a short insulin tolerance test after 1 week of nasal CPAP use in nondiabetics; however, no significant change was noted at 12 weeks in the nonobese subgroup. All subjects in these studies had severe OSA and BMI $>35 \mathrm{~kg} \cdot \mathrm{m}^{-2}$. Uncontrolled studies using the gold-standard hyperinsulinaemic euglycaemic clamp measurement also showed contrasting outcomes with both positive [4] and negative [31] results after 3 months.

There are several potential limitations to our study. First, we did not repeat imaging studies after the washout period and, hence, assumed that any positive effect of CPAP on fat stores would revert to baseline levels after washout. However, the length of the washout period was long (4 weeks) and we could not detect any order effect. Secondly, our sham CPAP compliance was lower than therapeutic CPAP, although the difference was small $(1 \mathrm{~h})$ and it would have been preferable to have longer nightly CPAP with both devices. More accurate measures of insulin sensitivity could have been added to improve the completeness of this component of the study; however, the protocol was considerably demanding and any additional measures may have resulted in increased study withdrawals. In addition, our study may not have been adequately powered to detect a difference in central adiposity. Nevertheless, our participant numbers are comparable with other studies $(n=16,22$ and 29) that showed a reduction in visceral fat $[7,8,10]$. Finally, we only had one female participant and, hence, our conclusions may be more applicable to the male OSA population. Future studies on females, particularly post-menopausal females, with OSA are necessary since there appears to be a preferential increase in visceral fat in this group [32].

In summary, this is the first randomised, sham-controlled study investigating the influence of CPAP on central adiposity over an 8 -week period. No differences in subcutaneous, visceral and hepatic fat were observed between the therapeutic and subtherapeutic CPAP groups. This suggests that 8 weeks of CPAP do not reduce central obesity in isolation and that additional concurrent measures, such as weight reduction, are probably required for improvement in cardiovascular and metabolic wellbeing. Further sham-controlled, randomised studies using CPAP for a longer duration may be necessary to detect a significant and clinically meaningful difference.

\section{SUPPORT STATEMENT}

This work was supported by Australian National Health and Medical Research Council project grant 301936 (to R.R. Grunstein), a Centre for Integrated Research and Understanding of Sleep Clinical Research Fellowship (to S. Sivam), a Health Professional Fellowship (571179; to C.L. Phillips), a Practitioner Fellowship (202916; to R.R. Grunstein) and a Career Development Fellowship (511929; to P.Y. Liu).

\section{CLINICAL TRIAL}

This study is registered with the Australian and New Zealand Clinical Trials Registry (www.anzctr.org.au), with identifier number ACTRN 12605000066684.

\section{STATEMENT OF INTEREST}

None declared.

\section{ACKNOWLEDGEMENTS}

We wish to thank a number of research staff at the Woolcock Institute of Medical Research (Glebe, NSW, UK). They include P. Gee, J. Dungan, A. Denotti, K. Melehan, G. Gauthier, D. Bartlett, D. Richards, N. Lai, M. Yee and G. Dungan.

\section{REFERENCES}

1 Young T, Palta M, Dempsey J, et al. The occurrence of sleepdisordered breathing among middle-aged adults. $N$ Engl J Med 1993; 328: 1230-1235.

2 Bonsignore MR, Esquinas C, Barceló A, et al. Metabolic syndrome, insulin resistance and sleepiness in real-life obstructive sleep apnoea. Eur Respir J 2012; 39: 1136-1143.

3 Lam JCM, Lam B, Yao TJ, et al. A randomised controlled trial of nasal continuous positive airway pressure on insulin sensitivity in obstructive sleep apnoea. Eur Respir J 2010; 35: 138-145.

4 Harsch IA, Schahin SP, Radespiel-Troger M, et al. Continuous positive airway pressure treatment rapidly improves insulin sensitivity in patients with obstructive sleep apnea syndrome. Am J Respir Crit Care Med 2004; 169: 156-162. 
5 Despres JP, Lemieux I, Bergeron J, et al. Abdominal obesity and the metabolic syndrome: contribution to global cardiometabolic risk. Arterioscler Thromb Vasc Biol 2008; 28: 1039-1049.

6 Vgontzas AN, Papanicolaou DA, Bixler EO, et al. Sleep apnea and daytime sleepiness and fatigue: relation to visceral obesity, insulin resistance, and hypercytokinemia. J Clin Endocrinol Metab 2000; 85: 1151-1158.

7 Trenell MI, Ward JA, Yee BJ, et al. Influence of constant positive airway pressure therapy on lipid storage, muscle metabolism and insulin action in obese patients with severe obstructive sleep apnoea syndrome. Diabetes Obes Metab 2007; 9: 679-687.

8 Chin K, Shimizu K, Nakamura T, et al. Changes in intra-abdominal visceral fat and serum leptin levels in patients with obstructive sleep apnea syndrome following nasal continuous positive airway pressure therapy. Circulation 1999; 100: 706-712.

9 Munzer T, Hegglin A, Stannek T, et al. Effects of long-term continuous positive airway pressure on body composition and IGF1. Eur J Endocrinol 2010; 162: 695-704.

10 Vgontzas AN, Zoumakis E, Bixler EO, et al. Selective effects of CPAP on sleep apnoea-associated manifestations. Eur J Clin Invest 2008; 38: 585-595.

11 Phillips CL, Yee BJ, Trenell MI, et al. Changes in regional adiposity and cardio-metabolic function following a weight loss program with sibutramine in obese men with obstructive sleep apnea. J Clin Sleep Med 2009; 5: 416-421.

12 Kohler M, Pepperell JC, Davies RJ, et al. Continuous positive airway pressure and liver enzymes in obstructive sleep apnoea: data from a randomized controlled trial. Respiration 2009; 78: 141-146.

13 Day CP. Non-alcoholic fatty liver disease: a massive problem. Clin Med 2011; 11: 176-178.

14 Norman D, Bardwell WA, Arosemena F, et al. Serum aminotransferase levels are associated with markers of hypoxia in patients with obstructive sleep apnea. Sleep 2008; 31: 121-126.

15 Chin K, Nakamura T, Takahashi K, et al. Effects of obstructive sleep apnea syndrome on serum aminotransferase levels in obese patients. Am J Med 2003; 114: 370-376.

16 Shpirer I, Copel L, Broide E, et al. Continuous positive airway pressure improves sleep apnea associated fatty liver. Lung 2010; 188: 301-307.

17 Phillips CL, Yee BJ, Marshall NS, et al. Continuous positive airway pressure reduces post prandial lipidemia in obstructive sleep apnea: a randomised, placebo controlled crossover trial. Am J Respir Crit Care Med 2011; 184: 355-361.

18 Sleep-related breathing disorders in adults: recommendations for syndrome definition and measurement techniques in clinical research. The Report of an American Academy of Sleep Medicine Task Force. Sleep 1999; 22: 667-689.

19 Positano V, Gastaldelli A, Sironi AM, et al. An accurate and robust method for unsupervised assessment of abdominal fat by MRI. J Magn Reson Imaging 2004; 20: 684-689.

20 Demerath EW, Ritter KJ, Couch WA, et al. Validity of a new automated software program for visceral adipose tissue estimation. Int J Obesity 2007; 31: 285-291.

21 Naressi A, Couturier C, Castang I, et al. Java-based graphical user interface for MRUI, a software package for quantitation of in vivo/ medical magnetic resonance spectroscopy signals. Comput Biol Med 2001; 31: 269-286.

22 Longo R, Pollesello P, Ricci C, et al. Proton MR spectroscopy in quantitative in vivo determination of fat content in human liver steatosis. J Magn Reson Imaging 1995; 5: 281-285.

23 Kullberg J, Brandberg J, Angelhed JE, et al. Whole-body adipose tissue analysis: comparison of MRI, CT and dual energy X-ray absorptiometry. Br J Radiol 2009; 82: 123-130.

24 Kuk JL, Katzmarzyk PT, Nichaman MZ, et al. Visceral fat is an independent predictor of all-cause mortality in men. Obesity (Silver Spring) 2006; 14: 336-341.

25 Nordestgaard BG, Benn M, Schnohr P, et al. Nonfasting triglycerides and risk of myocardial infarction, ischemic heart disease, and death in men and women. JAMA 2007; 298: 299-308.

26 Jang Y, Kim OY, Ryu HJ, et al. Visceral fat accumulation determines postprandial lipemic response, lipid peroxidation, DNA damage, and endothelial dysfunction in nonobese Korean men. J Lipid Res 2003; 44: 2356-2364.

27 Blackburn P, Lamarche B, Couillard C, et al. Contribution of visceral adiposity to the exaggerated postprandial lipemia of men with impaired glucose tolerance. Diabetes Care 2003; 26: 3303-3309.

28 Matikainen N, Manttari S, Westerbacka J, et al. Postprandial lipemia associates with liver fat content. J Clin Endocrinol Metab 2007; 92: 3052-3059.

29 West SD, Nicoll DJ, Wallace TM, et al. Effect of CPAP on insulin resistance and $\mathrm{HbA1c}$ in men with obstructive sleep apnoea and type 2 diabetes. Thorax 2007; 62: 969-974.

30 Coughlin SR, Mawdsley L, Mugarza JA, et al. Cardiovascular and metabolic effects of CPAP in obese males with OSA. Eur Respir J 2007; 29: 720-727.

31 Smurra M, Philip P, Taillard J, et al. CPAP treatment does not affect glucose-insulin metabolism in sleep apneic patients. Sleep Med 2001; 2: 207-213.

32 Simpson L, Mukherjee S, Cooper MN, et al. Sex differences in the association of regional fat distribution with the severity of obstructive sleep apnea. Sleep 2010; 33: 467-474. 